${ }^{1}$ Departamento de Medicina Interna. Pontificia Universidad Catolica de Chile. Santiago, Chile. 2Departamento de Hematología. Pontificia Universidad Catolica de Chile. Docente Universidad Católica de la Santísima Concepción, Chile. aResidente especialidad.

Conflicto de intereses: los autores declaran que no hay ningún conflicto de intereses con respecto a este escrito.

Recibido el 19 de mayo de 2014, aceptado el 18 de junio de 2015 .

Correspondencia a: Dr. Mauricio Sarmiento M. Departamento de Hematología y Oncología, Pontificia Universidad Catolica de Chile. Lira 85-4 $4^{\circ}$ piso. mauriciosarmiento@hotmail.com

\section{Síndrome hemofagocítico adquirido: reporte de casos de cuatro pacientes adultos tratados con protocolo HLH 94-04 y revisión de la literatura}

\author{
NICOLE BEFFERMANN C. ${ }^{1, a}$, JAVIER PILCANTE S., ${ }^{2, a}$, \\ MAURICIO OCQUETEAU T. ${ }^{2}$, MAURICIO SARMIENTO M. ${ }^{2}$
}

\section{Acquired hemophagocytic syndrome treated with HLH 94-04 chemotherapy protocol. Report of four cases}

Hemophagocytic syndrome is a severe condition of excessive immune activation that has a high mortality in the absence of treatment. The syndrome is classified as primary if associated with congenital or hereditary problems, or secondary/acquired if associated with infectious, autoimmune or oncology diseases. We report four adult cases of the syndrome, one with viral, two with autoimmune and one with idiopathic causes who were successfully treated with HLH 94-04 chemotherapy protocol. Our experience shows that a high index of suspicion, early diagnosis and an opportune therapy are essential in the treatment of this disease.

(Rev Med Chile 2015; 143: 1172-1178)

Key words: Cyclosporine; Etoposide; Fever of unknow origin; Lymphohistiocytosis, hemophagocytic)
$\mathrm{E}$ 1 síndrome hemofagocítico (SHF) en un raro y extremadamente grave desorden ocasionado por un estado de hiperactividad del sistema inmune. Si bien se describe desde 1939, hay un preocupante incremento de casos reportados en los últimos 10 años ${ }^{1}$. En esta revisión mostramos nuestra experiencia en 4 casos y revisamos brevemente las características del SHF.

\section{Caso 1}

Un hombre de 33 años, sin antecedentes mórbidos, consultó por una semana de fiebre y dolor abdominal. Como dato relevante sus dos hijas menores de 5 años tuvieron un cuadro respiratorio viral autolimitado durante la semana previa al inicio de los síntomas del paciente.
$\mathrm{Al}$ ingreso se objetivó fiebre y un examen físico sin alteraciones. Los exámenes de laboratorio realizados mostraron proteína $C$ reactiva $(\mathrm{PCR})$ elevada, hemograma normal, cultivos de sangre y orina negativos y perfil bioquímico normal. La radiografía de tórax y la tomografía axial computarizada (TAC) de abdomen y pelvis no mostraron hallazgos anormales. Se solicitó panel viral molecular de hisopado nasofaríngeo que mostró la presencia de virus parainfluenza. Pese al tratamiento sintomático el paciente persistió febril durante la primera semana de ingreso y desarrolló adenopatías cervicales dolorosas, artralgias de manos y rash evanescente. Se realizaron exámenes de control que mostraron alteración de las pruebas hepáticas con un patrón colestásico, sedimentación elevada, PCR en aumento, anemia normocítica normocrómica arregenerativa y trombocitopenia. 
Ante la ausencia de unidad diagnóstica se amplió el estudio con marcadores de autoinmunidad, pruebas de hepatitis viral y de vasculitis, todas resultando en rangos normales. Se planteó como posible diagnóstico la Enfermedad de Still, por lo que se solicitó ferritina que resultó elevada (1.776 $\mathrm{UI} / \mathrm{L}$, valor normal entre 40 y $290 \mathrm{UI} / \mathrm{L})$. En las siguientes $24 \mathrm{~h}$ la ferritina aumentó a $2.400 \mathrm{UI} / \mathrm{L}$ y el paciente desarrolló hepatoesplenomegalia. Se postuló el diagnóstico de SHF secundario a patología viral (parainfluenza 2) y con la urgencia de obtener material para diagnóstico histológico se realizó estudio medular que mostró células inflamatorias por citometría de flujo (CMF) y hemofagocitosis medular.

Se inició protocolo de quimioterapia HLH 94. Durante la hospitalización el paciente presentó de forma súbita compromiso de conciencia y falla respiratoria que requirió tratamiento intensivo. La resonancia magnética cerebral mostró un hematoma tálamoestriatal izquierdo, con mínimo desplazamiento de la línea media y efecto de masa. El paciente evolucionó con resolución espontánea del hematoma y el déficit motor.

Tras iniciar el protocolo de quimioterapia (QMT) HLH 94, los niveles de ferritina y las alteraciones hepáticas se normalizaron progresivamente. Se estudió un hermano del paciente por la posibilidad de realizar trasplante alogénico de precursores hematopoyéticos (Alo-TPH) de consolidación o rescate, resultando HLA idéntico. Sin embargo, este tratamiento no fue necesario pues tras 24 meses de seguimiento el paciente ha tenido una buena evolución, con valores de ferritina y hematopoyesis en rango normal. Presenta buena calidad de vida a los 36 meses de seguimiento.

\section{Caso 2}

Una mujer de 41 años de edad con antecedentes de obesidad y lupus eritematoso sistémico con compromiso cutáneo y articular leves, que consultó por $48 \mathrm{~h}$ de fiebre sin otras molestias. Como antecedente relevante la paciente se había realizado 3 semanas antes del inicio de los síntomas una gastrectomía en manga.

$\mathrm{Al}$ ingreso se objetivó fiebre y un examen físico sin alteraciones evidentes, con heridas quirúrgicas sin signos de infección. Los exámenes de laboratorio mostraron un hemograma sin anemia, con volumen corpuscular medio en 78 FML, PCR levemente elevada, discreta elevación de transaminasas (GOT $60 \mathrm{U} / \mathrm{L}, \mathrm{GPT} 31 \mathrm{U} / \mathrm{L}$ ), LDH elevada (332 U/L), urocultivo con presencia de enterococo faecalis sensible y hemocultivos negativos. Los exámenes de actividad lúpica resultaron negativos. Dada la cirugía bariátrica reciente y el VCM bajo se solicitó ferritina que resultó elevada (1.302 UI/L) y que se interpretó como secundaria a la infección aguda. Se inició tratamiento antibiótico logrando mejoría transitoria, pero persistiendo febril. Se realizó una TAC de abdomen que descartó filtración de gastrectomía y mostró esplenomegalia y adenopatías retroperitoneales en hilio esplénico y en cadenas ilíacas. Los exámenes de control mostraron anemia microcítica hipocrómica progresiva, PCR normal, urocultivo y hemocultivo sin crecimiento bacteriano, panel viral molecular respiratorio y exámenes de actividad lúpica ambos negativos. Se solicitó TAC de tórax, abdomen y pelvis que mostró derrame pleural bilateral leve, nódulos pulmonares inespecíficos, múltiples adenopatías supra e infradiafragmáticas menores a $1 \mathrm{~cm}$ y persistencia de la esplenomegalia. Se realizó estudio de los nódulos pulmonares de forma no invasiva el cual resultó negativo (beta d-glucano, galactomanana, PCR para CMV, VIH, IgM chlamydia y PCR pneumocystis jiroveci). Se sospechó síndrome linfoproliferativo y se solicitó PET TAC que mostró aumento de la captación glucídica de las adenopatías y del bazo (SUV mayor a 8). No se pudo realizar biopsia de linfonodo por difícil acceso quirúrgico. La paciente mostró aumento progresivo de la $\mathrm{LDH}$, las transaminasas y los triglicéridos y desarrolló pancitopenia. Se solicitó una nueva ferritina que resultó en 6.482 $\mathrm{UI} / \mathrm{L}$ con lo que se planteó posible SHF. Se realizó estudio de médula ósea que mostró celularidad aumentada sin evidencia de hemofagocitosis y sin malignidad. Las pruebas hepáticas y LDH persistieron al alza (LDH 3.585 U/L, GOT 1063 U/L, GPT 320 U/L, GGT 674 U/L, FA 330 mg\%) con serología viral negativa, por lo que se decidió realizar biopsia hepática que mostró hallazgos categóricos de hemofagocitosis. Horas después de realizada la biopsia hepática la paciente evolucionó con hematoma hepático extenso. Se logró controlar sangrado mediante embolización selectiva por radiología intervencionista. Durante la evolución se observó alza de ferritina hasta $74.583 \mathrm{U} / \mathrm{L}$ y LDH hasta $4.124 \mathrm{U} / \mathrm{L}$. 
Luego del inicio del protocolo de QMT HLH 04 las pruebas hepáticas se normalizaron y la ferritina disminuyó a valores normales. Se estudió una hermana de la paciente por la posibilidad de realizar Alo-TPH de consolidación, resultando HLA idéntica. Al momento de redactar este reporte, tras 1 y $1 / 2$ años de seguimiento, la paciente se encuentra con buena calidad de vida sin necesidad de trasplante.

\section{Caso 3}

Una mujer de 33 años sin antecedentes mórbidos de importancia consultó por varios días de fiebre, compromiso del estado general y sensibilidad a la palpación cervical. Al ingreso se encontró con taquicardia, sudorosa, con presencia de rash maculopapular generalizado y palpación dolorosa de la glándula tiroidea. Los exámenes de laboratorio iniciales mostraron hemograma y pruebas hepáticas normales y pruebas con patrón hipertiroideo (TSH 0,01 UI/mL y T4 libre $120 \mathrm{ug} / \%$ ). Ante la posibilidad diagnóstica de tiroiditis aguda se inició tratamiento con beta bloqueo oral logrando controlar la taquicardia pero con persistencia de la fiebre. Se realizó extenso estudio que fue negativo para infecciones, se detectaron pruebas hepáticas alteradas (GOT $1.200 \mathrm{U} / \mathrm{L}$ y GPT en $900 \mathrm{U} / \mathrm{L}$ ) $\mathrm{y}$ anticuerpos anti receptor de tiroides (TRAB) intensamente positivos. El estudio imagenológico con TAC mostró bocio difuso y adenopatias axilares y no se encontraron evidencias de malignidad o infecciones. La paciente evolucionó rápida y progresivamente con pancitopenia (hemoglobina 9 gr\%, leucocitos $2.300 / \mathrm{uL}$, plaquetas $65.000 /$ $\mathrm{uL})$, ferritina elevada (12.300 UI/L) y deterioro progresivo de la función hepática, manifestaciones no explicadas por la enfermedad de Graves. Para tratar de precisar la causa del compromiso multiorgánico se realizaron biopsias. La biopsia de piel mostró dermatitis espongiótica compatible con enfermedad de Still. La biopsia de médula ósea mostró hiperplasia reactiva y la biopsia ganglionar mostró linfadenitis no específica. Se realizó una segunda medición de ferritina que resultó en 34.000 UI/L. Ante el posible diagnóstico de SHF se inició tratamiento con protocolo HLH 04. Tras iniciar QMT la paciente presentó mejoría sintomática con normalización de la ferritina.

Luego de 18 meses de tratamiento, la pacien- te ha tenido una evolución favorable logrando una buena calidad de vida, con remisión de las alteraciones hepáticas y normalización de la hematopoyesis. Actualmente está en tratamiento satisfactorio de su enfermedad de Graves.

\section{Caso 4}

Una mujer de 21 años previamente sana ingresó por un mes de evolución de fiebre, compromiso del estado general y alteración de pruebas hepáticas. Al ingreso se encontró decaída $\mathrm{y}$ sin alteraciones al examen físico. Se realizaron exámenes de laboratorio que mostraron pancitopenia (hemoglobina 10 gr\%, leucocitos 1.900/ $\mathrm{uL}$, plaquetas $43.000 / \mathrm{mL}$ ) y alteración de pruebas hepáticas (GOT 1.800 U/L, GPT 1.300 U/L). Se realizó estudio de enfermedades infecciosas el cual fue negativo (hemocultivo, urocultivo, virus hepatotropos, mycoplasma, toxoplasma, leptospira, bartonella, brucella, rubéola, sarampión, VIH, parvovirus B19, citomegalovirus y Epstein Barr). Se realizó estudio reumatológico donde resultó ANA 1:40 patrón moteado y anti DNA por FARR, factor reumatoide y perfil ENA negativos con complemento normal. La paciente continuó con fiebre y pruebas hepáticas en deterioro. Se realizó TAC de tórax, abdomen y pelvis que mostró presencia de linfonodos pequeños difusos, derrame pleural laminar bilateral y hepatoesplenomegalia. Se realizó biopsia de linfonodos que mostró una adenitis no específica. Los niveles de ferritina resultaron en 23.460 U/L. Se realizó estudio medular que mostró hiperplasia linfoide y presencia de abundantes hemofagocitos. La paciente inició tratamiento con protocolo HLH 04 con buena respuesta clínica, con normalización de pruebas hepáticas y descenso de la ferritina hasta valores normales. Al momento de redactar este reporte la paciente lleva 24 meses de tratamiento sin complicaciones y con buena calidad de vida. La paciente no dispone de hermanos HLA compatibles.

\section{Discusión}

\section{Definición}

El SHF es una grave condición que se caracteriza por la activación exagerada del sistema inmune y aumento de la actividad linfocítica citotóxica y macrofágica, la que puede ser potencialmente 
fatal ${ }^{1}$. La ausencia de regulación de las vías de control críticas de la respuesta inmune genera un estado de inflamación extrema, acompañado de un aumento de los niveles de citoquinas y de la actividad de células histiocíticas ${ }^{2}$.

\section{Epidemiología}

El SHF es una rara condición que afecta principalmente a la población pediátrica, con una incidencia de 1:100.000 nacidos vivos en Estados Unidos de Norteamérica, con una incidencia mas elevada en países nórdicos. No existen estudios epidemiológicos en adultos, por lo que la incidencia real de esta enfermedad es desconocida, aunque hay un preocupante aumento del número de casos reportados en la literatura internacional ${ }^{1}$. La mortalidad descrita en pacientes sin tratamiento es mayor a $90 \%$ a 2 meses del diagnóstico, principalmente en aquellos con enfermedad neoplásica $\mathrm{u}$ homocigotos para mutaciones asociadas.

\section{Patogenésis}

El SHF se produce por una defectuosa desactivación de los macrófagos. En condiciones normales la actividad macrofágica es regulada por las células T CD8+ y las células NK, que por medio de la vía de las perforinas/grandzimas, inducen la apoptosis de los macrófagos activados a través de la vía de las caspasas. Esta citotoxicidad controlada es llevada a cabo por medio de un complejo sistema de unión célula-célula (sinapsis inmune) que activa un movimiento de vesículas con gran- dzimas a través de microtúbulos ${ }^{2,3}$. La falla en el control de la activación macrofágica y la ausencia de su apoptosis, son característicos en el SHF. Los genes responsables de esta función citotóxica están localizados en los cromosomas 6, 9, 10 y 17, siendo el más importante el gen de la perforina, el que se encuentra ubicado en el cromosoma 10 (10q21-22). Se han descrito diversas mutaciones genéticas que favorecen el defecto en la regulación macrofágica y se asocian con el SHF primario o hereditario, descritas en la Tabla 1.

\section{Clasificación}

Las razones de la defectuosa regulación del sistema inmune del SHF son variadas por lo que la mayoría de los autores concuerdan en clasificarlo primario y secundario. EL SHF primario se asocia a alteraciones genéticas específicas generalmente hereditarias y suele presentarse en los primeros meses de vida ${ }^{1}$. EL SHF secundario se asocia a alguna enfermedad o condición subyacente y suele presentarse en la adulte ${ }^{1-3}$. Si bien la edad de presentación suele ser concordante con la clasificación descrita, hay casos reportados de enfermos afectos por el SHF en la adultez, en quienes se han determinado alteraciones genéticas heterocigotas de manifestación tardía ${ }^{4,5}$. La Tabla 2 resume las principales causas del SHF secundario.

\section{Diagnóstico}

El SHF tiene una presentación clínica imprecisa y heterogénea. Los pacientes pueden presentarse

Tabla 1. Alteraciones genéticas asociadas a hemofagocitosis hereditaria

\begin{tabular}{|lll|}
\hline Enfermedad & Gen & Defecto fenotípico \\
\hline FHLH1 & Desconocido & Desconocido \\
\hline FHLH2 & PRF1 & Contenido vesicular \\
\hline FHLH3 & Munc 13.4 & Marcador vesicular \\
\hline FHLH4 & STX11 & Acoplamiento/ fusión \\
\hline FHLH5 & STXBP2 & Acoplamiento/ fusión \\
\hline Chediak-Higashi & LYST & Tráfico vesicular \\
\hline Griscelli II & RAB27a & Fusión vesicular \\
\hline Hermansky-Pudlak II & AP3B1 & Tráfico vesicular \\
\hline XLP1 & SH2D1A (SAP) & Citotoxicidad TCD 8+/NK \\
XLP2 & BIRC4 (XIAP) & Múltiples señales intracelulares \\
\hline
\end{tabular}

FHLH: Familiar hemophagocytic lymphohistyocitosis. XLP: X linked lymphoproliferative disease. 
Tabla 2. Condiciones asociadas a síndrome hemofagocítico adquirido

\begin{tabular}{|lll|}
\hline Infecciones & Enfermedades autoinmunes & Otras condiciones \\
$\begin{array}{l}\text { virus: Epstein-Barr, citomegalovirus, } \\
\text { herpes, virus de inmunodeficiencia } \\
\text { humana, influenza, parainfluenza }\end{array}$ & $\begin{array}{l}\text { Lupus eritematoso sistémico, } \\
\text { Enfermedad mixta del tejido conectivo, } \\
\text { esclerosis sistémica, Sjögren }\end{array}$ & $\begin{array}{l}\text { Inmunodeficiencia común variable, } \\
\text { asociada a X }\end{array}$ \\
bacterias: brucellosis, tuberculosis. & Artritis reumatoide & Enfermedad de Kawasaki \\
parásitos: leishmaniasis. & Enfermedad de Still & Leucemias y linfomas \\
Hongos & Poliarteritis nodosa & Fase acelerada del síndrome de Chediak \\
& Síndrome DRESS & Higashi \\
\hline
\end{tabular}

Tabla 3. Criterios diagnósticos de SHF según el estudio HLH 2004

A. Comprobación de alteración molecular consistente con HLH: mutación patológica de PRF1, UNC13D, Munc 18-2, Rab27a, STX11, SH2D1A, BIRC4

B. Cinco de los siguientes criterios deben cumplirse:

1. Fiebre $\geq 38,5^{\circ} \mathrm{C}$

2. Esplenomegalia

3. Citopenias (al menos 2 de 3 líneas celulares en sangre periférica):

- Hemoglobina $<9 \mathrm{~g} \%$

- Plaquetas < 100.000/uL

- Neutrófilos < 1.000/ul

4. Hipertrigliceridemia (TG ayunas $>265 \mathrm{mg} / \mathrm{dL}$ ) y/o hipofibrinogenemia $(<150 \mathrm{mg} / \mathrm{dL}$ )

5. Hemofagocitosis demostrada en médula ósea, bazo, ganglios linfáticos, hígado

6. Actividad celular NK ausente o disminuida

7. Ferritina $>500 \mathrm{UI} / \mathrm{L}$

(Si bien protocolo HLH-2004 usa ferritina $>$ 500, generalmente se ven niveles $>3.000$ en casos sugerentes y $>10.000$ en casos muy sospechosos)

8. CD 25 soluble elevado (cadena alfa de receptor soluble de IL-2)

Valores normales del laboratorio de referencia ( $>2$ desviaciones estándar del límite alto) son mejores que el valor absoluto de $>2.400 \mathrm{UI} / \mathrm{uL}$

Nota: Para el diagnóstico es suficiente el criterio A. En su ausencia se realiza con la sumatoria de los criterios descritos en B.

con fiebre de origen desconocido, pancitopenia, poliadenopatías, organomegalias y alteración de pruebas hepáticas entre otros. El compromiso neurológico se observa principalmente en pacientes pediátricos. El diagnóstico debe realizarse en pacientes con sospecha clínica, basado en los criterios diagnósticos HLH 2004 como se describen en la Tabla 3. Si bien la hemofagocitosis objetivada en biopsia es altamente sugerente del SHF, no es absolutamente necesaria. El estudio genético de formas primarias no se realiza de rutina en adultos dado que es de difícil acceso y por la baja incidencia de alteraciones genéticas en adultos. La determinación de IL 2 y receptor soluble de CD25 son herramientas útiles en el diagnóstico pero pocos centros disponen de este recurso. En la población pediátrica debe realizarse el estudio genético puesto que tiene consecuencias terapéuticas y de consejería.

\section{Tratamiento}

Independiente de la causa o factor desencadenante, el tratamiento del SHF se basa en los esquemas HLH 94 y 04 (Tabla 4). Si bien hay diversas 
Tabla 4. Esquema HLH 94 y 04 para el tratamiento del síndrome hemofagocítico (HLH)

Dexametasona $10 \mathrm{mg} / \mathrm{m}^{2} /$ día en semanas 1 y 2 , luego $5 \mathrm{mg} / \mathrm{m}^{2} /$ día en semanas 3 y $4 ; 2,5 \mathrm{mg} / \mathrm{m}^{2} /$ día en semanas 5 y 6 ; $1,25 \mathrm{mg} / \mathrm{m}^{2} /$ día en semana 7 , reduciendo dosis hasta suspender durante semana 8

Etopósido $150 \mathrm{mg} / \mathrm{m}^{2}$ dos veces por semana las primeras 2 semanas, luego una dosis semanal hasta cumplir 8 semanas Metotrexato intratecal asociado a hidrocortisona: máximo 4 dosis (semanal desde semana 3 a 6) en caso de compromiso neurológico o en caso de LCR comprometido:

a. $6 \mathrm{mg} \operatorname{MTX}(<1$ año de edad) $+4 \mathrm{mg}$ hidrocortisona

b. $8 \mathrm{mg} \operatorname{MTX}(1-2$ años de edad) $+6 \mathrm{mg}$ hidrocortisona

c. $10 \mathrm{mg} \operatorname{MTX}(2-3$ años de edad) $+8 \mathrm{mg}$ hidrocortisona

d. $12 \mathrm{mg} \mathrm{MTX} \mathrm{(>} 3$ años de edad) + $10 \mathrm{mg}$ hidrocortisona

Ciclosporina ajustada para niveles basales entre $250-300 \mathrm{ng} / \mathrm{mL}$.

(La ciclosporina varía en los dos protocolos. En el HLH 94 se inicia a la semana 9, mientras que en el HLH 04 se inicia al momento del diagnóstico).

opciones de tratamiento, Hentel et al ${ }^{6,7}$ demostraron que con este esquema se logra una sobrevida global de $55 \%$ a 6,2 años, siendo especialmente útil en el subgrupo de enfermos sin alteración genética predisponente, y secundarios a enfermedad viral. Los pacientes con SHF asociado a enfermedad reumatológica (también llamado síndrome de hiperactivación macrofágica) pueden ser tratados inicialmente con corticoides únicamente, con estrecho seguimiento y ante refractariedad agregar precozmente etopósido.

El Alo-TPH se reserva para pacientes con enfermedad refractaria o progresiva a pesar del tratamiento y en pacientes pediátricos portadores de mutaciones de genes asociados a $\mathrm{SHF}^{1,2,8}$. Las tasas de sobrevida global a 5 años se han estimado en $66 \%$ con tasas de mortalidad asociada al trasplante cercana a $20 \%$. El trasplante también puede considerarse en pacientes en que la causa del SHF esté asociado a neoplasia hematológica; en estos casos el Alo-TPH tendría doble indicación: la presencia de neoplasia hematológica grave y del SHF. Aún no hay manera de predecir el comportamiento clínico y la respuesta de cada paciente a la quimioterapia. Si bien el descenso y la velocidad con que se logra normalizar la ferritina son factores importantes ${ }^{9}$, la enfermedad tiene un curso impredecible. Por esto, es recomendable que se realice estudio de histocompatibilidad en donantes potenciales, que ante deterioro o pérdida de respuesta, permitan proceder con el Alo-TPH como último recurso. Con respecto a la búsqueda y selección del donante hay varias consideraciones a tener en cuenta. En la población pediátrica hay posibilidad de que coexistan alteraciones genéticas heredadas o familiares, por lo que deben seleccionarse con cautela los donantes emparentados, los cuales deben ser sometidos a test genéticos para evaluar eventuales SHF no diagnosticados. En adultos esta consideración tiene menor importancia pues la mayoría de los enfermos tienen SHF adquiridos. Cada vez hay más reportes en los que se describen pacientes trasplantados con donantes haploidénticos con tasas de respuesta a lo menos comparables con aquellos trasplantados con donante emparentado HLA idéntico ${ }^{8}$. El régimen condicionante para el trasplante (condicionamiento reducido o mieloablativo) debe seleccionarse caso a caso dependiendo de si hay enfermedad neoplásica de base y de pre exposición a quimioterapia. El seguimiento en el periodo post trasplante conlleva dificultades pues la reactivación del SHF puede tener presentaciones clínicas similares a infecciones propias de los pacientes inmunosuprimidos o simular una enfermedad injerto contra huésped en hígado o piel.

En los casos de pacientes refractarios a tratamiento con quimioterapia y Alo-TPH el pronóstico es sombrío. Se ha intentado reinducir remisión con nuevo trasplante o usando alemtuzumab, rituximab y plasmaféresis con respuestas variables ${ }^{10}$.

\section{Conclusiones finales}

El SHF es infrecuente y requiere un alto índice de sospecha pues sin tratamiento puede ser mortal. El enfoque del paciente inicia en el servicio de medicina interna donde el conocimiento previo del síndrome por parte de los hospitalistas es fundamental. En nuestros casos clínicos los pacientes 
tuvieron una evolución satisfactoria gracias a un rápido diagnóstico, con inicio precoz de la quimioterapia, soporte vital en unidad de cuidados intensivos y adecuado tratamiento de las complicaciones. En los casos de adultos es necesario descartar causa secundaria, especialmente infecciones virales, neoplasias o enfermedades autoinmunes. Tanto los protocolos HLH 94 como el HLH 04 siguen siendo los pilares del tratamiento de este síndrome, los cuales han logrado reducir la alta mortalidad de estos pacientes.

Al comparar con las publicaciones en población chilena ${ }^{11-13}$ destaca que en su mayoría son reportes de casos, secundarios a enfermedades reumatológicas, y tratados de manera no protocolizada con uso de diferentes tipos de corticoides, ciclofosfamida y varios inmunosupresores. Hay un reporte en particular que amerita especial mención $y$ es el realizado por Peña y cols. ${ }^{13}$ en el cual se describen cinco pacientes con cáncer y trasplante hepático, en el que se llegó al diagnóstico post mortem en 3 enfermos y hubo una mortalidad de 80\%. En nuestro reporte, en que los enfermos tuvieron enfermedades predisponentes autoinmunes o infecciosas, se muestra que con la incorporación de la posibilidad de SHF en los algoritmos diagnósticos de FOD se genera un índice de sospecha que permite realizar un diagnóstico apropiado de manera precoz y un tratamiento efectivo.

En nuestra serie es evidente que ante la persistencia de fiebre, de manera fortuita o intencional, se realizó solicitud precoz de ferritina lo cual permitió instaurar una sospecha diagnóstica que luego se confirmó con estudio histológico. La medición de la ferritina en este tipo de pacientes es un recurso económico y ampliamente disponible en los laboratorios clínicos que permite aproximarse rápidamente al diagnóstico precoz y así iniciar tratamiento.

El SHF es una grave enfermedad que conlleva alta mortalidad sin tratamiento oportuno. Sin embargo con una detección precoz basada en un alto índice de sospecha, se puede lograr que los pacientes sobrevivan con buena calidad de vida.

\section{Referencias}

1. Schram A, Berliner N. How I treat hemophagocytic lymphohistiocytosis in adult patient. Blood 2015; pre- published online march 10 .

2. Jordan M, Allen C, Weitzman S, Filipovich A, McClain K. How I treat hemophagocytic lymphohistiocytosis. Blood 2011; 118 (15): 4041-52.

3. Reiner A, Spivak J. Hematophagic histiocytosis. A report of 23 new patients and a review of the literature. Medicine (Baltimore) 1988; 67(6): 369.

4. Zhang K, Jordan MB, Marsh RA, Johnson JA, Kissell $\mathrm{D}$, Meller J, et al. Hypomorphic mutations in PRF1, MUNC13-4, and STXBP2 are associated with adult-onset familial HLH. Blood 2011; 118 (22): 5794-8.

5. Clementi R, Emmi L, Maccario R, Liotta F, Moretta L, Danesino C, et al. Adult onset and atypical presentation of hemophagocytic lymphohistiocytosis in siblings carrying PRF1 mutations. Blood 2002; 100 (6): 2266.

6. Henter J, Samuelsson-Horne A, Aricò M, Egeler R, Elinder G, Filipovich A, et al. Histocyte Society. Treatment of hemophagocytic lymphohistiocytosis with HLH-94 immunochemotherapy and bone marrow transplantation. Blood 2002; 100 (7): 2367.

7. Trottestam H, Horne A, Aricò M, Egeler R, Filipovich A, Gadner H, et al. Histiocyte Society. Chemoimmunotherapy for hemophagocytic lymphohistiocytosis: longterm results of the HLH-94 treatment protocol. Blood 2011; 118 (17): 4577.

8. Nishi M, Nishimura R, Suzuki N, Sawada A, Okamura $\mathrm{T}$, Fujita $\mathrm{N}$, et al. Reduced-intensity conditioning in unrelated donor cord blood transplantation for familial hemophagocytic lymphohistiocytosis. Am J Hematol 2012; 87: 637.

9. Lin TF, Ferlic-Stark LL, Allen CE, Kozinetz CA, McClain KL. Rate of decline of ferritin in patients with hemophagocytic lymphohistiocytosis as a prognostic variable for mortality. Pediatr Blood Cancer 2011; 56: 154.

10. Worth AJ, Nikolajeva O, Chiesa R, Rao K, Veys P, Amrolia PJ. Successful stem cell transplant with antibody-based conditioning for XIAP deficiency with refractory hemophagocytic lymphohistiocytosis. Blood 2013; 121 (24): 4966-8.

11. Young P, Venditti JE, Preiti V, Bullorsky E, Bruetman JE. Hemophagocytic syndrome: Report of four cases. Rev Med Chile 2011; 139: 224-9.

12. Álvarez M, López T, Ballesteros F, Fuentealba C, Pacheco D, Marinovic M. Caso Clínico Artritis Reumatoide Juvenil de inicio sistémico y Síndrome de Activación Macrofágica. Reumatología 2005; 21 (4): 237-41.

13. Peña C, Valladares X, Cabrera ME. Secondary hemophagocytic syndrome: report of 5 cases. Rev Med Chile 2013; 141: 475-9. 